\section{As funções poética e metalinguística na interpretação de texto*}

\author{
The poetic and metalinguistic \\ functions in text interpretation
}

José Américo Bezerra SARAIVA (UFC) jabsaraiva@gmail.com

Recebido em: 11 de abr. de 2019. Aceito em: 03 de out. de 2019.

*Escrito no final da década de 1990 e ainda inédito, este artigo sofreu pouquíssimas modificações porque sua publicação aqui tem por propósito mais homenagear o mestre Paulo Mosânio Teixeira Duarte do que apresentar resultados de pesquisa recente.

\title{
00000000000
}

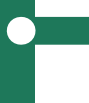

SARAIVA, José Américo Bezerra. As funções poética e metalinguística na interpretação de texto. Entrepalavras, Fortaleza, v. 10, n. esp., p. 75-102, ago. 2020. DOI: 10.22168/2237-63218 esp1704.

Vi prodígios de inteligência e intuição numa existência tumultuada pela Verdade. No caminho aberto pelo gigante, a cada papo e afago de alma, o topo oco de minha cabeça ganhava qualquer ou nenhuma direção. Exímio em tudo, para quem o conheceu de perto, é mestre eterno a ensinar a líquida consistência do ser. Guardo-o em mim. Um zilhão de vezes: obrigado, Paulo Mosânio!

Resumo: Com este artigo, homenageamos a memória do professor, orientador e amigo Paulo Mosânio Teixeira Duarte, cuja presença inspiradora constituía-se sempre, nos mais variados ambientes, da academia à mesa de bar, promessa de felicidade para quem buscava bons e elevados papos, conduzidos pela potência e espontaneidade de uma gaia(ta) ciência, própria do cearense culto que, no caso dele, não se levava excessivamente a sério nem deixava a máscara social colar-se à cara. Vocacionado por "onde nem tempo nem espaço" a refletir sobre o mistério da vida e os seus sentidos, o mestre era ponta de lança aferindo, e aferindo-se, entre bem-humorado e colérico, a vida 
como experiência filosófica. O texto que aqui apresento é parte da glosa de um mote sugerido por ele para o meu mestrado na UFC: função poética e motivação semântica. Havia o mestre proposto o tema "o estatuto da locução em língua portuguesa" para minha dissertação. Imaginei-me especialista no assunto atravessando a vida acadêmica e desanimei. Queria algo mais estimulante. Então, ele propôs uma pesquisa sobre a função poética e a motivação semântica. Acatei, sem deixar, no entanto, de ajustar o foco prático da pesquisa para a produção poético-cancional de um artista brasileiro pelo qual nutro respeito, admiração e amor: Caetano Veloso. É nesse espírito, portanto, isto é, num misto de saber e sabor, que daremos curso à sugestão de que existe certa similaridade entre as funções metalinguística e poética, sugestão encampada por Jakobson (s/d), desenvolvida por Lopes (s/d) e partilhada pelo mestre Paulo Mosânio. Antes, porém, faremos remissão a outros autores que vislumbraram a aproximação para, no final do artigo, fornecer uma síntese comparativa entre eles.

Palavras-chave: Função poética. Função metalinguística. Interpretante.

Abstract: In this article, we pay tribute to the memory of the professor, supervisor and friend Paulo Mosânio Teixeira Duarte, whose inspiring presence was always, in many different environments, from the university to the bar, a promise of happiness for those who used to seek good and high-level conversations, guided by the power and spontaneity of a gaia(ta) science, specific to the cultured Cearense, who, in his case, did not take himself too seriously or let the social mask stick to his face. Devoted to "where neither time nor space" reflect on the mystery and meaning of life, the master was a spearhead, assessing himself, from good-humored to choleric, and assessing life as a philosophical experience. The text I present here is part of the remarks of a theme suggested by him for my Master Degree at UFC: the poetic function and semantic motivation. He had suggested the theme "the status of the noun phrase in Portuguese" for my dissertation. I imagined myself an expert on the subject going through my academic life and became discouraged. I wanted something more stimulating. He then proposed a research on poetic function and semantic motivation. I accepted, however, adjusting the practical focus of the research to the poetic production of the songs of a Brazilian artist whom I respect, admire and love: Caetano Veloso. It is in this spirit, therefore, that is, in a mixture of knowledge and taste, that we will proceed to the suggestion that there is a certain similarity between the metalinguistic and poetic functions, a suggestion encapsulated by Jakobson (nd), developed by Lopes (nd) and shared by the master Paulo Mosânio. Before, however, we will refer to other authors who glimpsed the approximation, in order to, at the end of the article, provide a comparative synthesis between them.

Keywords: Poetic function. Metalinguistic function. Interpretant.

\section{Introdução}

Convicto da necessidade de uma abordagem interdisciplinar do fenômeno linguístico, Jakobson (s/d) bebe em fontes diversas. E é nesse clima que desenvolve sua teoria das funções da linguagem, em que é patente, sobretudo, a influência dos teóricos da comunicação. Aliás, a propósito disso declara Jakobson:

De fato, os linguistas têm muito a aprender da teoria da comunicação. Um processo de comunicação normal opera com um codificador e um decodificador. O decodificador recebe a mensagem. Conhece o código. A mensagem é nova para ele e, por via do código, ele a interpreta. (JAKOBSON, s/d, p. 23) 
Nessas bases, Jakobson amplia o modelo triádico das funções da linguagem de Bühler (1950) e preceitua um outro, com seis funções, tomando como fundamento os fatores intervenientes no processo de comunicação, isto é, contexto, remetente, destinatário, mensagem, código e contato.

Cada um desses seis fatores determina uma função da linguagem diferente. Assim, se a mensagem está orientada para o contexto, a função é referencial; se para o remetente, função emotiva; se para o destinatário, função conativa; se para o contato, função fática; se para o código, função metalinguística; se ênfase é dada à mensagem, função poética.

As funções da linguagem, assim entendidas, podem todas ocorrer numa mesma mensagem e isto é o que sucede amiúde. $\mathrm{Na}$ realidade, diz-nos Jakobson, "a diversidade das mensagens não reside no monopólio de alguma dessas diversas funções, mas numa diferente ordem hierárquica de funções. A estrutura verbal de uma mensagem depende basicamente da função predominante" (Jakobson, s/d, p. 123).

De acordo com o pensamento de Jakobson, cada uma dessas funções possui marcas linguísticas características. Por exemplo, numa mensagem cuja função preponderante é a referencial, verificamos a ênfase no contexto, e, por conseguinte, um predomínio da terceira pessoa do verbo, matiz comum em mensagens de caráter científico, cuja finalidade é fundamentalmente transmitir informação teórica. Mensagens desse tipo possuem uma dimensão cognitiva preponderante. A função emotiva, em termos linguísticos, é marcada pela primeira pessoa do verbo, pela interjeição, pelos adjetivos que veiculam, no mais das vezes, o ponto de vista do emissor, por alguns advérbios e por sinais de pontuação. A função conativa se destaca pelo verbo na segunda pessoa e pelo uso do imperativo e do vocativo, que constituem as principais marcas linguísticas desse tipo de função. Característica da função fática são expressões consagradas pelo uso e pouco relevantes do ponto de vista informativo, tais como: bom dia!, como vai?, alô! A tautologia é traço característico da faticidade.

Baseada no código, a função metalinguística pressupõe a existência de uma língua-objeto da qual se fala por intermédio de uma metalíngua, que, por ser melhor conhecida, funciona como modelo decodificador daquela. Por fim, dirigida para os elementos da mensagem efetivamente utilizados, temos a função poética. Segundo Jakobson, tal função aprofunda a dicotomia fundamental entre signos e objetos (s/d, p. 128), ao promover o caráter palpável dos signos. 
v. 10 (esp.)

75-102 ago. 2020

Jakobson busca, em seguida, definir a função poética em termos linguísticos. Para tanto, recorda os dois modos de arranjo utilizados no comportamento verbal, seleção e combinação. Num ato de comunicação, o falante escolhe, por exemplo, unidades léxicas para atualizá-las no discurso, combinando-as. A seleção, diz-nos Jakobson, é feita com base em equivalência, semelhança e dessemelhança, sinonímia e antonímia, e a combinação se baseia na contiguidade. Por essa razão é que define a função poética como "a função que projeta o princípio de equivalência do eixo de seleção sobre o eixo de combinação" (JAKOBSON, s/d, p. 130). E acrescenta: "a equivalência é promovida à condição de recurso constitutivo da sequência" (JAKOBSON, s/d, p. 131).

Tais equivalências projetadas sobre o eixo da combinação são de natureza bem distintas. Elas existem no nível fonológico, morfológico, sintático, léxico, semântico. Sob a denominação de paralelismos, Coquet (1975 p. 37) apresenta os tipos infrarrelacionados:

a. os paralelismos gramaticais (ou sua ruptura);

b. os paralelismos dependentes do eixo das convenções (ou sua ruptura);

c. os paralelismos fônicos e prosódicos (ou sua ruptura);

d. os paralelismos semânticos (ou sua ruptura).

\section{Similaridade entre função poética e metalinguística}

Jakobson (s/d), em seu clássico artigo Linguística e Poética, já ensaiava aproximar a função poética da metalinguística por operarem ambas com um mesmo mecanismo, projeção das equivalências do eixo da seleção sobre o eixo da combinação. Porém, logo rechaça tal aproximação, conforme atesta o excerto abaixo:

Pode-se objetar que a metalinguagem também faz uso sequencial de unidades equivalentes quando combina expressões numa sentença equacional: A = A ('A égua é a fêmea do cavalo'). Poesia e metalinguagem, todavia, estão em oposição diametral entre si; em metalinguagem, a sequência é usada para construir uma equação, ao passo que em poesia é usada para construir uma sequência (JAKOBSON, s/d, p. 130).

O linguista russo-americano constata esta oposição diametral entre as funções metalinguística e poética e para por aí, deixando de extrair da comparação os traços que as aproximam.

Riffaterre (1973, p. 146-9) faz algumas achegas às funções jakobsonianas. Diverge do mestre russo-americano no que tange às 
relações de dominância das funções numa mensagem, embora reconheça o mesmo número de funções. Prefere, em vez da função poética, admitir uma função estilística, que, a seu ver, juntamente com a função referencial, está sempre presente na mensagem. Aquela é a única que está centrada na mensagem, ao passo que as outras se direcionam para algo exterior a ela. Riffaterre assevera que "a comunicação é estruturada por cinco funções direcionais e que sua intensidade (desde a expressividade até a arte) é modulada pela função estilística." (RIFFATERRE, 1973, p. 146).

A função estilística afasta a mensagem de um grau zero, de uma pura referencialidade, graduando a intensidade das outras funções. Afirmação perigosa, pois pode conduzir à interpretação da função poética como reforço, ênfase, que Riffaterre (1973, p. 32) rejeita.

Por reconhecer a função estilística como moduladora da intensidade das demais funções é que Riffaterre volta seu interesse para a relação entre elas. E é nesses termos que compreende a imbricação existente entre a função estilística e a metalinguística. Esta função é regulada por aquela, observa ele. A função metalinguística torna remetente e destinatário capazes de verificar se estão utilizando o mesmo código e "tal verificação", assinala Riffaterre, "está orientada para a mensagem, uma vez que a atualização do código, com as ambiguidades possíveis, é a própria razão de ser da mensagem poética" (RIFFATERRE, 1973, p. 147). Em outros termos, dado o grau de opacidade (peculiaridade da mensagem poética), remetente e destinatário frequentemente voltam ao código para assegurar-se de que utilizam o mesmo código. Riffaterre acrescenta ainda:

Num emprego pensado da língua, particularmente nos textos escritos, as glosas ou esclarecimentos sobre o código poucas vezes são realmente necessárias (sic): o remetente tem toda liberdade de evitar qualquer obscuridade ao atualizar o código; a função metalinguística constitui então mais uma forma de realce (emphasis) (RIFFATERRE, 1973, p. 147).

É evidente que Riffaterre está com razão quanto à necessidade que o decodificador tem, muitas vezes, de recorrer ao código para compreender uma mensagem poética, dado seu alto grau de opacidade. Todavia, é também evidente que não se deve considerar a função estilística como moduladora da função metalinguística, em termos de puro código.

Parece-nos que Riffaterre prende-se em demasia ao momento da codificação, no que concerne à função metalinguística, restringindo assim o conceito de metalinguagem. Ora, o fato de o remetente ter toda liberdade para evitar obscuridades na atualização do código não implica, 


\section{v. 10 (esp.}

75-102 ago. 2020

necessariamente, que o destinatário receberá a mensagem isenta delas. Este pode recorrer com frequência a dicionários e gramáticas, no caso de textos escritos. No caso de textos falados, a informação tradutora pode ser requerida ao próprio remetente da mensagem. Portanto, se as funções estilística e metalinguística aproximam-se, não é devido a tais razões, mas sim ao fato de ambas requererem uma informação tradutora, como veremos mais adiante.

Acrescente-se ainda que Riffaterre reconhece que essas duas funções diferem entre si na medida em que uma sequência metalingual paralisa o ato de comunicação criando um círculo vicioso, algo irritante. A função estilística, por sua vez, entendida como moduladora das demais funções, modifica uma sequência metalingual extraindo-lhe a eficácia, isto é, regula a intensidade da função metalinguística, sem, todavia, suprimi-la.

Lopes (s/d, p. 68-9), em nota de pé de página, também aborda o assunto e sugere ter a função poética o mesmo estatuto básico da metalinguística. Para chegar à aproximação das duas funções tradicionalmente separadas, parte ele da noção de interpretante, de Peirce (1995), a qual emerge de uma relação triádica objeto-signointerpretante.

O interpretante é definido como um signo que interpreta outro, garantindo o que se chama semiose ilimitada (cf. ECO, 1974, p. 18; ECO, 1991a, p. 26; ECO, 1991b, p. 60-2), a autonomia e a perpétua circulação sígnicas. Todosignodetermina, pois, uminterpretante, elepróprioumsigno . Interpretante não é, frisemos bem, nem o intérprete nem a interpretação, não obstante Eco (1974, p. 17) reconheça que, no próprio Peirce, uma confusão desse tipo pode ser gerada. Na tríade retro, o interpretante emerge como terceiro, ou, como terminologiza o semioticista russoamericano, uma terceiridade. Lúcia Santaella adverte que, "embora o intérprete e o ato interpretativo sejam uma das partes embutidas na relação" entre signo e interpretante, "eles não se confundem com o interpretante" por duas razões. Primeiro, porque "o signo é sempre um tipo lógico, geral, muito mais geral do que um intérprete particular, existente, psicológico - que dele faz uso". Segundo, porque "o interpretante, que o signo como tipo geral está destinado a gerar, é também ele um outro signo" (SANTAELLA, 1995, p. 86-87). "O interpretante é uma propriedade objetiva que o signo possui em si mesmo, haja um ato interpretativo particular que a atualize ou não" (SANTAELLA, 1995, p. 85). Logo, o interpretante consiste num signo que interpreta outro signo. 
Com base na teoria do interpretante, sumariamente caracterizada acima, Lopes estabelece que a diferença entre a função metalinguística e a poética é que, na primeira, os elementos que interpretam a mensagem estão no código, ao passo que, na segunda, os elementos interpretantes da mensagem estão contidos na própria mensagem. Passemos, nesse momento, a palavra ao próprio Lopes:

No fundo, qual é a diferença? Num dos casos (o das funções metalinguísticas, estudadas por Jakobson), a informação tradutora, no plano de conteúdo da mensagem-objeto, provém do código, da langue; no presente caso, o da função poética, a informação tradutora (interpretante, segundo Peirce), do plano de conteúdo da mensagem-objeto, provém dessa mesma mensagem, ou de partes dela guindadas à condição de subcódigo metalinguístico. (LOPES, s/d, p. 69 - Itálicos do autor)

Lopes acrescenta ainda que, ao lado do papel desempenhado pelo interpretante do código, é importante reconhecer o papel desempenhado pelo interpretante do contexto (linguístico) e conclui: "Esse interpretante do contexto, outro nome da função poética, é dotado de função metalinguística a igual título que o interpretante do código". (LOPES, s/d, p. 85)

Por tais razões é que Lopes reelabora a concepção de função metalinguística, preconizando dois tipos: a propriamente dita, cujo interpretante provém do código, e a poética, cujo interpretante provém do contexto linguístico.

A tal concepção corresponde o esquema abaixo:

Figura 1 - Função metalinguística e função poética

\section{Funções metalinguísticas}

Função metalinguística propriamente dita (interpretante do código)

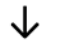

Função poética (interpretante do contexto)

Fonte: Lopes, s/d.

Dada a aproximação entre função metalinguística e função poética, sugerida por Jakobson bem como por Riffaterre, e levada a efeito por Lopes, é que chegamos a uma reformulação parcial do esquema das funções da linguagem proposto por Jakobson.

Admitimos, assim, a existência de cinco funções, sendo que a função poética, a exemplo do que sustenta Lopes, deve ser considerada como um tipo de metalinguagem lato sensu, cuja informação tradutora advém do contexto, enquanto, no caso da função metalinguística propriamente dita, a informação tradutora vem do código. 
v. 10 (esp.)

75-102 ago. 2020

Vale lembrar que não são poucos os autores que desenvolvem esse tema, sobretudo quando fazem referência à tensão que se estabelece entre os dois eixos da linguagem, o paradigmático e o sintagmático, no momento da interpretação de um texto. Na seç̧ão subsequente, elencamos alguns autores que guardam estreita relação entre si quando o assunto é o processo de interpretação e o papel que o contexto nele exerce.

\section{Informação tradutora do código e do contexto}

Os autores abaixo relacionado, embora partindo de arcabouços teóricos diferentes, tendem a ver o fenômeno da informação tradutora, no processo de compreensão de um texto, de maneira semelhante, isto é, a seu modo, cada um desses autores postula, como se verá, um significado extradiscursivo e outro intradiscursivo, em constante tensão.

Jan Mukarovsky

Em um artigo intitulado A denominação poética e a função estética, Mukarovsky (1978, p. 159-66) distingue a denominação poética das demais espécies de denominação (as quais chama de comunicativa). Tal distinção assenta no fato de que a primeira, ao contrário do que ocorre com a segunda, não é determinada por sua relação com a realidade significada, mas pelo contexto em que se encontra inserida. Assim, é o contexto que 'sugere ao leitor a significação atribuída à palavra pela decisão individual e única do poeta', conforme evidencia o excerto:

Podemos afirmar até mesmo que todos os procedimentos estilísticos (os diversos meios fônicos, por exemplo), que provocam reações semânticas recíprocas entre as palavras que ligam, estão a serviço da tendência essencial da poesia para determinar a denominação sobretudo pela sua inserção no contexto (Tynianov) (MUKAROVSKY, 1978, p. 170).

Cumpre salientar que Mukarovsky parte do quadro tripartite das funções da linguagem de Bühler para sugerir uma função estética, oposta à representação, à expressão e ao apelo, que perfazem o que Mukarovsky designa por funções práticas. A função estética não se orienta para instâncias exteriores à língua, com fins que ultrapassam o signo linguístico, antes transforma o signo mesmo em centro das atenções (MUKAROVSKY, 1978, p. 161). As funções práticas assim são 
designadas por determinarem as conexões da língua com a praxis, donde emerge o significado, ao passo que a função estética tende a desautorizar essas conexões, fazendo emergir um significado com base no contexto linguístico, ou a denominação poética, nos termos de Mukarovsky.

A denominação poética como emergente do contexto, tal qual nos faz ver Mukarovsky, é, pois, a resultante das imbricações textuais em nível fônico, morfológico, sintático e semântico. O autor, todavia, não oferece maiores subsídios, de modo a delinear os parâmetros para a especificação da noção de contexto, que, por si só, é muito vaga.

\section{Michael Riffaterre}

Riffaterre (1989) vê igualmente a interpretação do sentido poético como originária do contexto, das relações semânticas que se encontram inteiramente dentro do texto. Guardadas uma e outra diferença de enfoque, persevera na linha de uma estilística fundada no contexto ${ }^{1}$, não na norma, muito menos no sistema, uma vez que as dificuldades decorrem de ser esse um sistema de possibilidades ${ }^{2}$. Riffaterre repudia a interpretação fundamentada apenas no eixo das significações verticais, isto é, na língua, que, a seu ver, no caso do texto poético, "desencaminha" o leitor.

Na semântica do poema, diz-nos Riffaterre, o eixo das significações é horizontal; o texto constitui, por si só, seu próprio sistema referencial. Destarte, a função referencial no texto poético é exercida de significante a significante, de tal forma que certos significantes sejam percebidos pelo leitor como variantes de uma mesma estrutura 3 .

De acordo com Riffaterre, esse eixo horizontal:

${ }^{1}$ Com base no supraexposto, cria-se uma estilística do desvio, basicamente sintagmática, na qual desponta a noção de microcontexto e macrocontexto (cf. RIFFATERRE, 1973, p. 66-8). Vale lembrar aqui que contexto não é tomado em sua acepção corrente: "O contexto linguístico é um pattern linguístico rompido por um elemento imprevisível" (RIFFATERRE, 1973, p. 56). A propósito, em obra muito anterior, Riffaterre (1973, p. 62) assevera que "o contexto, inseparável em definição do processo estilístico, $1^{0}$ ) é automaticamente pertinente (o que é necessariamente verdadeiro para a norma); $2^{\circ}$ ) é imediatamente acessível por ser codificado, de modo que não precisamos recorrer a uma vaga e subjetiva Sprachgefuhl; $3^{\circ}$ ) é variável e forma uma série de contrastes com os processos estilísticos sucessivos. Só esta variabilidade pode explicar por que uma unidade linguística adquire, modifica ou perde seu efeito estilístico em função de sua posição, por que cada desvio da norma não é necessariamente um fato de estilo e por que efeito de estilo não implica em anormalidade".

2 Acerca da noção de sistema de possibilidades, vejam-se "Sistema, norma e falar concreto", in COSERIU, Eugenio. Teoria da linguagem e linguística geral, 1979.

3 Note-se como esta passagem lembra-nos as tematizações e figurativizações da semântica discursiva da teoria semiótica de Greimas. 


\section{v. 10 (esp.)}

75-102 ago. 2020 ...é representado materialmente pelo sintagma: é, portanto, organizado por uma sobreposição de estruturas. Primeiramente, pela estrutura linguística. Em seguida, pela estrutura estilística, série de contrastes com relação às normas contextuais, que asseguram a percepção da mensagem como forma. Em terceiro lugar, pelas estruturas temáticas, isto é, as estruturas cujas variantes são temas. Em quarto lugar, e aqui tocamos naquilo que é exclusivo do poema, pela estrutura lexical. Ou seja, as semelhanças formais e posicionais entre certas palavras do texto, semelhanças que são racionalizadas, interpretadas em termos de significação. Essas palavras, de fato, parecem repetir a mesma mensagem porque se assemelham morfologicamente ou têm funções análogas e porque suas semelhanças são enfatizadas. (RIFFATERRE, 1989, p. 31-2)

\section{Rolk Kloepfer}

O esquema das funções da linguagem de Jakobson foi objeto de um sem-número de ressalvas, entre as quais a de Kloepfer (1984), que, assumindo os conceitos semióticos de Morris (1985)4, admite ser um significante alçado à condição de signo mediante a relação que estabelece: a) com alguém que o possa utilizar, b) com aquilo a que se refere e c) com outros signos. Dessa tríplice relação surgem, respectivamente, as dimensões pragmática, semântica e sintática, que determinam igualmente funções em três níveis. A função semântica (referencial para Jakobson) se subclassifica em sigmática (referência a objetos da 'realidade aceita') e semântica em sentido restrito (referência relativa às nossas representações). A função pragmática se subcategoriza nas funções: situacional, pessoal (que incluem a emotiva e a conativa de Jakobson), accional e lingual. A função sintática, por sua vez, se subdivide em sintática em sentido restrito e textual.

Kloepfer reúne as funções emotiva e conativa de Jakobson em uma única função, a pessoal, a exemplo do que foi sugerido por Halliday (1976, 1978 e 1985) através da função interpessoal, evitando assim separar artificialmente emissor e receptor, coisa que Vanoye (1986) criticou no modelo hexádico de Jakobson. Kloepfer postula, ainda, uma função situacional, relacionada a uma situação concreta, espaçotemporalmente constituída, na qual se usa um canal que torna possível a comunicação, e, vale lembrar, inspirada na função contextual de D.

${ }_{4}$ Charles Morris (1985), seguindo os ensinamentos de Peirce, foi quem primeiro delineou uma divisão da semiótica em sintática, semântica e pragmática, na tentativa de circunscrever os domínios desta área do saber. Para Eco (1995, p. 219), um tal delineamento tende a configurar a semiótica como uma confederação de três disciplinas diferentes, cada qual com seu objeto específico, ou seja, nestes termos, semiótica passaria a ser um rótulo tão geral como é o de ciências naturais. 
Hymes. Além das já citadas funções, o autor admite uma função accional, ligada, de modo mais ou menos direto, à ação linguística (em que o autor inclui a plenitude dos contextos sociais), e a função lingual, referente às respectivas sublínguas (ou variedades, na terminologia sociolinguística), determinadas pela classe social, grupo etário, região etc.

Além das funções acima, Kloepfer (1984, p. 45) menciona as funções metalinguística e poética, aquela voltada para um código, veículo possibilitador da construção de mensagens e da intercompreensão, e esta direcionada para a mensagem, enquanto lugar do processo da desautomatização/atualização, como procedimento poético geral.

Tanto a função metalinguística como a poética buscam uma informação tradutora, um interpretante ${ }^{5}$. No primeiro caso, a informação tradutora é proveniente do código. No segundo, ela provém da própria mensagem.

No que tange à função poética em particular, podemos afirmar que ela atribui peculiar relevância ao contexto, que desautomatiza o signo da língua para atualizar um outro, o signo retórico (ou ideológico). Para falarmos em termos hjelmslevianos, trata-se da instauração de uma nova função sígnica em que um dos functivos, o plano da expressão, é já uma função sígnica.

A desautomatização pressupõe a automatização", "fenômeno de associação imediata do signo, ou de apenas uma de suas partes, a um determinado sentido, a um determinado conceito ou a determinados fatos" (KLOEPFER, 1984, p. 50), fenômeno que configura o código como o conjunto de todas as regularidades semânticas, sintáticas e pragmáticas que pressupõem uma comunicação eficaz. Nesses termos, todos os elementos, partes do código e suas inter-relações são susceptíveis de automatização.

O processo de desautomatização é inverso do de automatização. Tem-se desautomatização quando a associação imediata do significante com o significado, em uma de suas três dimensões (semântica, sintática e/ou pragmática), é desautorizada, evidenciando a natureza da função sígnica, relação entre expressão e conteúdo.

Cumpre ressaltar que Kloepfer estende o conceito à esfera do pragmático, exorbitando a proposta original de Jakobson.

${ }_{5}$ Segundo Peirce (1995, p. 46), um interpretante é um segundo signo criado na mente de uma pessoa a partir de um primeiro que lhe é dirigido, representâmen, e ao qual é equivalente ou talvez mais desenvolvido. Isto é, o interpretante pode ser entendido como outra representação que se refere ao mesmo objeto imediato.

${ }^{6}$ O termo automatização foi tomado de empréstimo ao Formalismo Russo. 
v. 10 (esp.)

75-102

ago.

2020

(...) quando dizemos 'bonjour', à noite, em vez de durante o dia, quando o falante a um 'merci' do interlocutor responde com um 's'il vous plaît' em vez de um 'il n'y a pas de quoi' como equivalente de 'bitte' (ou não responde mesmo), ou quando conta ao polícia o acidente dramaticamente (em vez de o relatar), o processo semiótico automático é interrompido no seu todo ou pelo menos nos seus elementos. A nossa atenção é, por meio do signo, concentrada no próprio signo. A este processo inverso chama-se desautomatização. Atualizada ou desatualizada pode ser não só a relação Sa-Se no signo, mas também o funcionamento do signo, ou seja, o funcionamento pragmático, semântico ou sintático (KLOEPFER, 1984, p. 50).

Pela passagem supratranscrita, pode-se constatar que a extensão conceitual do termo significado em Kloepfer não apenas abrange o significado semântico, mas também o significado pragmático, dependente da situação comunicativa. Nesse particular, o autor revelase favorável a uma compreensão menos restritiva de significado, a exemplo dos teóricos dos atos de fala.

\section{Edward Lopes}

Para Lopes (1978), o contexto constitui uma das instâncias de interpretação de um texto ${ }^{7}$, mais precisamente a instância mediadora entre uma língua e uma ideologia. Lopes recorre a Peirce (1995) para erigir sua teoria dos interpretantes, segundo a qual haveria: a) um limiar mínimo de significação de um discurso, constituído, no caso dos discursos verbais, pelo interpretante do código linguístico; b) um limiar máximo, constituído pelo interpretante ideológico; e c) um nível intermediário, representado pelo interpretante do contexto, cabendo a este o papel de estatuto mediador entre língua e ideologia.

De acordo com esses três níveis, organizar-se-iam três espécies de signos: os signos da língua (E R C1), os signos do contexto (E R C2) e os signos retóricos (ou ideológicos) (E R C3). Saliente-se que, tal como faz Hjelmslev (1975), Lopes parte da noção de signo como função entre uma expressão e um conteúdo e, por via de consequência, define os dois últimos signos com base numa função sígnica já realizada, ou numa semiótica, uma vez que os planos da expressão dos signos contextuais e retóricos são já constituídos por signos:

7 O termo texto, em Lopes (1978), deve ser compreendido como a resultante da interpretação de um discurso, isto é, uma dada leitura, para cuja construção podem ter contribuído um ou mais de um dos três níveis semióticos. 
Figura 2 - As três espécies de signos, segundo Lopes, 1978.

\section{Signo retórico (nível 3) Signo do contexto (nível 2) Signo da língua (nível 1)}

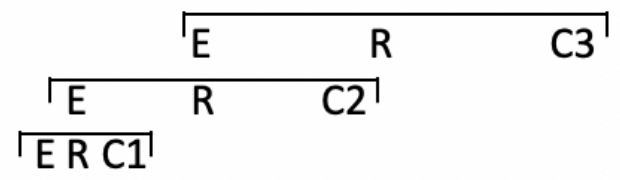

Fonte: Lopes (1978).

ou em termos de significante (Se) e significado (So):

Figura 3 - Os signos em termos e significante e significado

\section{Signo retórico (nível 3) Signo do contexto (nível 2) Signo da língua (nível 1)}

Fonte: Lopes (1978).

A partir desses três níveis de significação é que Lopes postula os três tipos de semiose operados na interpretação de um discurso, a saber: a) semiose extradiscursiva, baseada nos interpretantes do código linguístico; b) semiose intradiscursiva, baseada nos interpretantes do contexto linguístico; e c) semiose heterodiscursiva, baseada nos interpretantes ideológicos ${ }^{8}$.

Um fato chama-nos a atenção nas postulações de Lopes. Tratase do papel que o contexto desempenha na interpretação de um discurso para que este último se torne texto. Os interpretantes contextuais, na qualidade de mediadores entre língua e cultura, desempenham um papel, senão mais importante, pelo menos equivalente ao dos interpretantes do código e da cultura. Portanto, Lopes, assim como fazem Mukarovsky, Riffaterre e Kloepfer, salienta o papel do contexto na construção do sentido, contexto que, em Lopes, opera desautomatizando (para usarmos um termo de Kloepfer) a simples semiose denotativa (extradiscursiva) para instaurar uma nova semiose, a conotativa.

\footnotetext{
${ }^{8}$ Nessa altura, algumas semelhanças entre a proposta de Lopes e a de Riffaterre podem ser identificadas. Este autor fala numa significação vertical em oposição a uma significação horizontal, a do texto poético, e aquele lida com os significados paradigmático e sintagmático, operados, respectivamente, nas semioses extradiscursiva e intradiscursiva.
} 
v. 10 (esp.)

75-102 ago.

2020
Umberto EcO

Para postular um modelo semântico reformulado, Eco (1991b) parte de uma crítica à noção de referente e define o significado como unidade cultural.

De acordo com Eco, ligar a verificação de um significante ao objeto a que se refere (prática que se infiltrou por toda moderna reflexão acerca dos signos a partir do conhecido diagrama de Ogden e Richards (1976)) conduz-nos a dois problemas: a) faz depender o valor semiótico do significante de seu valor de verdade; b) obriga a individuar o objeto a que o significante se refere. Isto não é, com efeito, sempre possível, na medida em que existem signos que não possuem um referente (Bedeutung) ${ }^{9}$, enquanto entidade física: unicórnio, centauro, por exemplo, que nem por isso deixam de funcionar como signos. Como o próprio Eco assevera: "para a Semiótica, os signos interessam como forças sociais. O problema da mentira (ou falsidade), importante para os lógicos, é pré ou pós-semiótico" (ECO, 1974, p. 14). "A presença dos referentes, sua ausência, ou sua inexistência não incidem no estudo de um símbolo enquanto usado numa certa sociedade em relação a determinados códigos" (ECO, 1991b, p. 23).

O signo é na realidade uma unidade cultural cujo referente é também ele cultural, pois toda tentativa de dizer o que é o referente de um signo implica o uso de "termos de uma entidade cultural abstrata, a qual não passa de convenção cultural" (ECO, 1991b, p. 15). Veja-se o difundido exemplo da unidade cultural /neve/, que, para os esquimós, corresponde a pelo menos quatro unidades culturais, conforme os estados em que a neve se encontra. Essa multiplicidade de unidades culturais modifica o léxico esquimó, de modo a fazer corresponder a cada unidade cultural um termo específico.

O significado assim entendido faz-nos ver a linguagem como fenômeno social e, por conseguinte, dinâmico, uma vez que as definições e explicações dos termos em jogo numa dada mensagem são fornecidas pela própria cultura que os utiliza. E mais: os termos empregados nas definições e explicações são, por sua vez, também definíveis em outros termos, de tal sorte que não se pode romper as fronteiras do universo semiótico, universo das unidades culturais. Eis o que Eco (1974, p. 17) diz a respeito desse processo ininterrupto:

\footnotetext{
9 Em Semiótica e Filosofia da Linguagem, Eco reflete sobre a acepção do termo alemão Bedeutung na obra de Frege (1978) e intenta mostrar que, embora o filósofo afirme ser Bedeutung o objeto a que o signo se refere, sua noção de objeto é mais ampla do que a de objeto concreto ou classe de objetos concretos. Segundo Eco, o objeto de Frege é "qualquer sujeito de juízo" (ECO, 1991c, p. 69).
} 
Cada definição era uma nova mensagem linguística (ou visual), a qual, por sua vez, devia ser esclarecida nos seus próprios significados graças a outras mensagens linguísticas que definiriam as unidades culturais trazidas pela mensagem precedente. A série dos esclarecimentos que circunscrevem num movimento sem fim as unidades culturais de uma sociedade (as quais sempre se manifestam sob a forma de significantes que as denotam) é a cadeia do que Peirce chamava de interpretantes (ECO, 1974, p. 17).

Uma vez que o significado de um signo, visto como unidade cultural, é fornecido pelos interpretantes, que não passam de outros signos, num processo ad infinitum, urge esclarecer o conceito peirciano de interpretante.

Segundo Eco (1974, p. 18), "a noção de interpretante assustou muitos estudiosos que se apressaram em exorcizá-la tomando-a por outra coisa (interpretante $=$ intérprete ou destinatário da mensagem)". O semiólogo italiano adverte, todavia, que tal equívoco deve logo ser evitado porque o interpretante independe de um intérprete: na verdade ele é aquilo que garante a validade do signo ainda que na ausência do intérprete.

E o que é signo? Peirce (1995, p. 46) define-o como aquilo, representâmen, "que, sob certo aspecto ou modo, representa algo para alguém. Dirige-se a alguém, isto é, cria, na mente dessa pessoa, um signo equivalente, ou talvez um signo mais desenvolvido". A esse segundo signo, criado na mente de uma pessoa a partir de um primeiro, Peirce chama interpretante. O interpretante então é um signo que interpreta outro signo e que, para ser interpretado, requer a intervenção de outro signo, e assim por diante ${ }^{10}$. A essa altura, diz-nos Eco (1974, p. 18), abrir-se-ia:

um processo de semiose ilimitada, que, embora paradoxal, é a garantia única para a fundação de um sistema semiológico capaz de justificar-se a si mesmo e unicamente com seus próprios meios. A linguagem seria então um sistema que se esclarece por si, mediante sucessivos sistemas de convenções que se explicam reciprocamente (ECO, 1974, p.18).

De acordo com a perspectiva semiológica adotada por Eco (1974, p. 18), a noção de interpretante abrange não apenas os signos linguísticos, mas diversas outras formas, quer dizer, o interpretante pode ser:

\footnotetext{
${ }^{10}$ Peirce (1995) opera com duas categorias de objeto: o dinâmico e o imediato. Aquele é a coisa-em-si (Kant), o continuum (Hjelmslev), o que estimula a produção do signo e que nunca é capturável em sua totalidade. Este é a maneira como o objeto dinâmico é dado pelo signo, ou seja, é o próprio significado.
} 
v. 10 (esp.)

75-102 ago. 2020
- um signo equivalente (ou aparentemente equivalente) em outro sistema comunicacional (caso do desenho de um cão correspondente à palavra /cão/);

- o indicador apontado para o objeto isolado, talvez subentendendo um elemento de quantificação universal ("todos os objetos como esse");

- uma definição científica (ou ingênua) nos termos do próprio sistema de comunicação (/sal/ significando 'cloreto de sódio');

- uma associação emotiva que adquire valor de conotação fixa (/cão/ significando 'fidelidade');

- uma simples tradução do termo em outra língua.

Conforme esse modo de ver, qualquer entidade dessas pode constituir-se num dos functivos de uma função sígnica, quer dizer, expressão ou conteúdo (significante ou significado). Assim é que 'sal' pode ser o interpretante de $/ \mathrm{NaCl} /$ e vice-versa. Assim também "um punhado de sal pode tornar-se o interpretante de /sal/, bem como o signo gestual e fisionômico que imita quem distribui pitadas de substância salgada sobre a ponta da língua" (ECO, 1974, p. 19).

Para Eco, a noção de interpretante tal qual ele a entende, pode ser retraduzida como segue: "o interpretante é o significado de um significante, entendido na sua natureza de unidade cultural ostentada através de outro significante para mostrar sua independência (como unidade cultural) em relação ao primeiro significante" (ECO, 1974, p. 19).

Uma tal concepção de significado, como unidade cultural definível mediante outros signos, dispara o processo que Eco denomina semiose ilimitada, em que um signo remete a outro, e assim por diante, mecanismo cuja melhor representação seria a do modelo Quillian (ECO, 1991b, p. 112). Um dicionário representaria a estagnação desse processo semiótico, pelo menos é o que se pode dizer, conforme Eco, acerca de algumas propostas linguísticas de descrição do sistema de conteúdo de uma língua, a exemplo da clássica proposta Katz-Fodor ${ }^{11}$.

Eco (1991a, 1991b, 1991c) demonstra a insuficiência dos modelos de dicionário baseados nas propostas da análise sêmica, sobretudo por tentarem operar com primitivos inanalisáveis. Os adeptos dessa análise, como sabemos, aspiram a restringir os inventários das figuras de conteúdo, de modo a alcançarem um número limitado de primitivos.

${ }^{11}$ Para ver esta proposta, consulte-se Lobato (1977). 
Ora, é exatamente contra esse postulado que se insurge o semioticista italiano. Para ele, as figuras de conteúdo devem ser compreendidas como interpretantes, na acepção que Peirce atribui a esse termo. E, como vimos, o interpretante é um outro signo que interpreta um primeiro, também aquele interpretável mediante outro signo e assim por diante. Esse mecanismo, denominado por Eco princípio de interpretação, afasta de vez a possibilidade de se trabalhar com modelos semânticos globalizantes que operem com primitivos inanalisáveis. Tais primitivos poderiam, no máximo, ser postulados como nós últimos de algumas árvores de um dicionário parcial, oriundas do consenso histórico-cultural radicado no modo de pensar de uma civilização. Eis aí a função de um dicionário.

Admitamos, tendo como base esse consenso históricocultural, que certos interpretantes, enquanto marcas ou propriedades, sejam hierarquizáveis e que alguns desses interpretantes ocupem os nós últimos de uma representação em árvore. Tal assunção, embora artificial, é, sem dúvida, bastante útil para analisar porções mais ou menos estáveis dos universos semânticos, como os campos semânticos do assento ou das relações de parentesco, por exemplo. O que não se deve fazer, no entanto, é esquecer a artificialidade desse preito. Além disto, devemos admitir que lidamos, o mais das vezes, com universos semânticos instáveis, em que o significado de um dado lexema é-nos fornecido a partir das relações contextuais entre esse lexema e os demais que o ladeiam ou a partir das circunstâncias em que foi ele proferido. Acrescente-se a isto que até mesmo a hierarquização das propriedades dicionariais estão sujeitas a uma reordenação operada pelo contexto e/ ou pela circunstância de enunciação.

Pelas razões acima é que Eco (1991b) afirma não haver, numa semântica de interpretantes, entidades metalinguísticas nem universais semânticos, porque toda interpretação é passível de nova interpretação. Ademais, num modelo como esse, toda hierarquização de interpretantes resulta provisória, tendo em vista que o contexto e/ou as circunstâncias de enunciação é que orientam a organização hierárquica dos interpretantes.

A partir daí, Eco vai postular um modelo semântico reformulado baseado na noção peirciana de interpretante, que não negligencia o contexto e leva em conta instruções pragmaticamente orientadas: a enciclopédia, que Eco assim define: 
v. 10 (esp.)

75-102

ago.

2020

(...) a enciclopédia é uma hipótese reguladora com base na qual, na ocasião das interpretações de um texto (seja ele uma conversa na esquina ou a Bíblia), o destinatário decide construir uma porção de enciclopédia concreta que lhe permita reconhecer como característica do texto ou do emissor uma série de competências semânticas (ECO, 1991b, p. 114).

Em outra passagem, ele afirma:

O modelo atém-se à ideia de uma semântica de instruções, com formato enciclopédico, orientada para a inserção contextual do termo analisado, segundo o modo de inferência: se se pressupõe p, então se emprega a expressão no contexto q. Subtrair essas pressuposições da vaguidade das normas pragmáticas e inserilas numa representação semântica é fundamental para explicar a força persuasiva que resulta do emprego dos termos (ECO, 1991b, p. 130).

Como se vê, o modelo semântico reformulado objetiva inserir na representação semântica todos os interpretantes codificados (inclusive as conotações que dependem das denotações correspondentes), juntamente com as seleções contextuais e/ou circunstanciais. Tais seleções "distinguem os diferentes percursos de leitura de um semema ${ }^{12}$ como enciclopédia, e determinam a atribuição de muitas denotações e conotações" (ECO, 1991b, p. 94). Não devemos todavia ver, nas denotações e conotações assim atribuídas, a "matéria de um conhecimento empírico ad hoc dos referentes, mas elementos de informação codificados, ou seja, unidades semânticas do mesmo tipo das marcas, salvo que desenvolvem uma função de DESVIO (no sentido ferroviário do termo)" (ECO, 1991b, p. 130).

A fim de clarificar ainda mais esse modelo de descrição semântica, Eco refere à palavra baleia, que pode ser lida diferentemente de acordo com o contexto em que ele ocorra. Para um zoólogo, por exemplo, trata-se de um semema altamente hierarquizado e organizado de tal forma que as propriedades secundárias dependam daquelas mais gerais, numa espécie de árvore semelhante à de Katz-Fodor. Para um autor de bestiários medievais, o semema, também organizável em forma de árvore, tem como uma de suas marcas o ser peixe, e não mamífero, como é para o zoólogo. Para o homem comum contemporâneo, trata-se de um semema um tanto desconexo em cujo corpo se identificam, como coexistentes, as propriedades de ser peixe e mamífero.

Eco adverte que o semema, na verdade, não deve ser entendido

${ }^{12}$ Semema é uma unidade semântica estruturada compreendendo percursos de leitura mutuamente exclusivos que produzem incompatibilidades semânticas. 
como um conjunto de marcas hierarquizadas, mas hierarquizáveis, o que se dá, com frequência, a partir do contexto e/ou das circunstâncias de enunciação, que operam como dispositivo de magnificação/narcotização de propriedades semânticas.

Ao tratar da metáfora, por exemplo, Eco (1984, 1991b, 1991c) alude a um processo de reordenação de semas ${ }^{13}$, operado pelo contexto e/ ou pelas circunstâncias de enunciação, que provocam uma enfatização/ narcotização de semas, de modo a reorganizar hierarquicamente as propriedades de um dado semema, isto é, seus interpretantes.

A esse mesmo fenômeno refere-se Riffaterre quando assevera que:

a sequência verbal tem um efeito alternativamente cumulativo e eliminatório. Ela destaca os semas comparáveis e elimina os que não o são, retendo, das palavras, apenas os semas que elas têm em comum. Em resumo, opera uma filtragem semântica. Essa filtragem resulta inteiramente da contiguidade das palavras no sintagma: é ela que impõe a comparação (RIFFATERRE, 1989, p. 31).

Nas palavras de Riffaterre (abaixo transcritas), vê-se uma tomada de posição análoga à assumida por Eco, quanto à imobilidade a que está condenado um modelo semântico de base dicionarial, incapaz de dar conta deste processo de reordenação sêmica característico de um texto de natureza metafórica.

As combinações verbais mudam de aspecto, seu sentido modifica-se constantemente com a progressão da leitura. Toda interpretação que tende a imobilizar esse mecanismo conduzindo o texto ao real e ao atomismo estático do dicionário só pode desconhecer a função da poesia como experiência e alienação (RIFFATERRE, 1989, p. 37).

Eco (1991c, p. 187-8) vai além da simples magnificação/ narcotização de semas. Delineia cinco regras para a interpretação cotextual, a propósito da metáfora. São elas:

- Construa-se uma primeira representação componencial do semema metaforizante (parcial e experimental). Chamese ao semema metaforizante de veículo. Esta representação deve magnificar somente as propriedades que o cotexto sugeriu como relevantes, narcotizando as outras. Esta operação representa uma primeira tentativa abdutiva.

13 Sema é uma unidade mínima de significação, ou seja, uma propriedade semântica mínima, compreendida na hierarquização do semema. 
v. 10 (esp.)

75-102 ago. 2020
- Localize-se na enciclopédia (localmente postulada ad hoc) um outro semema que possua um ou mais dos mesmos semas (ou marcas semânticas) do semema veículo e que, ao mesmo tempo, apresente outros semas 'interessantes'. Torne-se este semema um candidato ao papel de semema metaforizado (teor). Se houver mais sememas em competição para este papel, tentem-se outras abduções, com base em indícios cotextuais. Fique claro que por 'os mesmos semas' se entendem os semas exprimíveis através do próprio interpretante. Por outros semas 'interessantes' entendem-se somente os representáveis por interpretantes diferentes, mas de modo que possam ser opostos segundo algumas incompatibilidades hipercodificadas (como aberto/fechado, morto/vivo, e assim por diante).

- Selecione-se uma ou mais destas propriedades ou semas diferentes e construa-se sobre eles uma árvore de Porfírio, de modo que estes pares de oposições se conjuguem num nó superior.

- Teor e veículo apresentam uma relação interessante quando suas propriedades ou semas se encontram num nó comparativamente muito alto da árvore de Porfírio. Expressões como /semas interessantes/ e /nó comparativamente mais alto/ não são vagas, porque se referem a critérios de plausibilidade cotextual. Semelhanças e diferenças podem ser avaliadas somente de acordo com o possível sucesso cotextual da metáfora e não há critério formal que estabeleça o grau 'exato' de diferença e a posição 'exata' na árvore de Porfírio. Segundo estas regras, partese das relações metonímicas (de sema para semema) entre dois sememas diferentes e, controlando a possibilidade de uma dupla sinédoque (que interessa tanto o veículo quanto o teor), aceita-se em conclusão a substituição de um semema pelo outro. Uma substituição de sememas, portanto, aparece como o efeito de uma dupla metonímia realizada por uma dupla sinédoque. Podemos, portanto, passar para a quinta regra.

- Controle-se, com base na metáfora suposta, se se podem localizar novas relações semânticas, de modo a enriquecer ulteriormente o poder cognitivo do tropo. 
Numa semântica desse tipo, fundada na noção de enciclopédia, perde-se, com efeito, muito do acabamento formal próprio de um dicionário. Todavia, uma semântica assim constituída reflete com maior fidelidade os mecanismos envolvidos no processo comunicativo, pois faz ver quão dependente do contexto (linguístico e/ou extralinguístico) é o significado de uma dada unidade léxica, particularmente se se trata de contextos metafóricos. Como vimos, semas conotativos periféricos podem ser alçados à condição de centrais, de acordo com determinações contextuais e/ou situacionais. Esse processo apenas recebe um tratamento adequado num modelo semântico aberto, que permita um redimensionamento sêmico de um semema, em função do contexto em que ele ocorre e a partir da base reticular de interpretantes culturalmente relacionados a um dado item lexical.

\section{Síntese}

Conforme vimos, Mukarovsky (1978) fala de uma denominação poética emergente do contexto, oposta a uma denominação comunicativa, com base no código. Riffaterre (1989) distingue um significado vertical de um significado horizontal, este oriundo do contexto, a partir de uma filtragem semântica, e aquele oriundo do código. Lopes (1978) diferencia um significado extradiscursivo de um significado intradiscursivo, fundamentado em bases semelhantes. E Eco (1984) refere-se a um processo de narcotização e/ou magnificação de semas operado pelo contexto.

Podemos ver, nas propostas de cada um desses autores, alguns pontos de convergência. O primeiro deles é o reconhecimento (implícito em alguns casos e explícito em outros) de que o código, embora aparentemente estável numa dada sincronia, caracteriza-se pela dinamicidade, ou seja, tem por característica ser instavelmente estável. Noutras palavras, o discurso tem como pressuposto de sua compreensão estar construído segundo um código pré-estabelecido, estável, socialmente aceito como tal. Porém, o discurso pode operar alterações nesse código, isto é, o discurso redimensiona o código, daí sua instabilidade ${ }^{14}$.

O segundo ponto de convergência, decorrente do primeiro, está no fato de os autores postularem um significado paradigmático,

\footnotetext{
${ }^{14}$ Saussure, em seu célebre Curso de Linguística Geral, já trata do assunto ao abordar o tema da imutabilidade e mutabilidade do signo linguístico. Reconhece que a parole, através da massa falante e do tempo, opera mutações na langue.
} 
v. 10 (esp.)

75-102 ago. 2020 estabilizado em termos de dicionário, e um significado sintagmático, que emerge da pressão contextual, uma vez que o contexto pode reordenar hierarquicamente o complexo sêmico, que é o semema. Como vimos, tanto Mukarovsky como Riffaterre e Lopes admitem, no mínimo, duas fases na interpretação de um lexema: uma paradigmática, que instaura o sentido socialmente estabilizado, institucionalizado, dicionarial, e outra sintagmática, fruto de pressões contextuais, que validam a interpretação paradigmática ou refutam-na, provocando, nesse caso, uma reorganização na hierarquia sêmica de um semema.

Em Eco (1984), o contexto opera de forma semelhante. Funciona como um filtro que reordena hierarquicamente os semas de um semema, mediante magnificação ou narcose de semas, apontando para um percurso de leitura.

Eco entende o lexema como algo que dispara uma série de associações sêmicas, que conduz de um signo a outro, de um interpretante a outro, originando um feixe de semas que constitui o semema. Esse feixe de semas não deve porém ser entendido como hierarquizável apenas contextualmente, como às vezes parece sugerir Eco. Em outra obra sua, Os Limites da Interpretação (1995), admite existir, no que diz respeito aos lexemas, semas mais institucionalizados que outros, isto é, semas que os falantes relacionam automaticamente a certos lexemas, razão por que Eco postulará um sentido literal.

Cotejando as propostas supra, percebe-se que o significado sintagmático muitas vezes se funda a partir da desautomatização do significado dicionarial, como sugere Kloepfer. Para nos certificarmos disto, basta vermos o papel que o contexto nelas assume. O contexto opera, muitas vezes, desautomatizando a função sígnica automatizada dicionarialmente para atualizar uma nova função sígnica, fundada na anterior e passível também de automatização ${ }^{15}$.

Os termos utilizados pelos autores denunciam a interseção de suas propostas neste ponto:

- denominação comunicativa / denominação poética (Mukarovsky);

- significado vertical / significado horizontal (Riffaterre);

- automatização / desautomatização (Kloepfer).

- interpretanteextradiscursivo/interpretanteintradiscursivo (Lopes);

\footnotetext{
${ }^{15}$ Por este processo, podem-se explicar, por exemplo, fenômenos como o da conotação.
} 
- sentido literal / narcotização e magnificação de semas, em função do contexto (Eco).

Tais oposições apontam para uma mesma direção: a função do contexto enquanto instaurador da significação, por confirmação ou refutação, parcial ou total, de um significado automatizado, dicionarial, institucionalizado.

Das propostas acima, as duas últimas, a de Lopes e a de Eco, são as que mantêm uma relação mais estreitada. Procederemos agora a uma comparação entre elas, a fim de buscar uma síntese.

Tanto Lopes quanto Eco fundamentam-se na noção peirciana de interpretante. Lopes (1978), por exemplo, admite, como vimos, a existência de três interpretantes: a) um interpretante do código, cuja função é "traduzir a mensagem à luz das informações fornecidas pelo código de partida que o organizou" (LOPES, 1978, p. 34); b) um interpretante do contexto, "cuja função é a de localizar, na contiguidade sintagmática, a lei de similaridade que preside ao arranjo de toda a sequência dotando-a de uma certa redundância informacional" (LOPES, 1978, p. 35); e c) um interpretante ideológico, "cuja função é decodificar a mensagem enquanto prática social, a partir dos códigos e discursos alheios que formam o complexo dos sistemas modelizantes através dos quais uma sociedade se interioriza em cada um dos indivíduos que a integra" (LOPES, 1978, p. 37).

Eco (1991b), por sua vez, em consonância com Peirce, entende o interpretante como aquilo que um signo produz na 'quase-mente' que é o intérprete. Assinala que, para se estabelecer o significado de um significante é necessário recorrer a outro significante que nomeie o primeiro. Esse processo dispara uma semiose ilimitada, posto que o interpretante de um signo é sempre outro signo, que só pode ser interpretado mediante outro signo e assim por diante.

Não obstante professe a semiose ilimitada como processo interpretativo e, a partir disso, reconheça o semema como um feixe de traços não hierarquizados, mas hiearquizáveis, de acordo com contextos e circunstâncias, ECo (1995) admite um sentido literal, a partir do qual nos sentimos autorizados a extrapolar todos os sentidos possíveis de uma dada mensagem. Essa assunção parece-nos aproximá-lo de Lopes, uma vez que o sentido literal tende a ser interpretado a partir das regras estabelecidas pelo código em que se forjou a mensagem. Assim sendo, como quer Lopes, o código (extradiscursivo) constitui uma primeira instância no ato interpretativo. Nessa altura, uma pergunta se impõe: o que esse autor quer dizer com o termo código? 
v. 10 (esp.)

75-102 ago. 2020

Lopes (1978) utiliza o termo código para referir-se tanto à língua, quanto à mensagem e à ideologia (enquanto imago semiotica). Como vimos, o código extradiscursivo serve tanto para a codificação da mensagem quanto para sua decodificação, pelo menos inicialmente. Em seguida, entram em jogo o código da mensagem e o código ideológico (nessa ordem), para reforçar a função sígnica fundada no código extradiscursivo ou para instaurar uma nova função sígnica, fundada naquela. Esse processo, entre código, contexto e ideologia, pode acarretar mutações no código que serviu de ponto de partida para a elaboração da mensagem. Nesses termos, embora o código constitua um pressuposto para a mensagem, ele deve ser entendido como algo instável, em construção permanente, não de todo sistematizável.

Nessa altura, pode-se verificar a íntima relação que se estabelece entre os três tipos de código postulados por Lopes (1978), tão estreitamente ligados que não é possível dizer com precisão o que é o código extradiscursivo, mormente se o compararmos com o código ideológico e tentarmos estabelecer fronteiras entre eles. Com efeito, parece-nos que, de acordo com Lopes (1978), o código extradiscursivo são a gramática e o léxico. Mas, o que se pode entender por léxico em Lopes? Trata-se do dicionário? Se assim for, então qual é a sua extensão? Aqui nos vemos novamente diante do problema da falta de limites precisos entre dicionário e enciclopédia.

Eco (1991c), por sua vez, faz um mea culpa ao mostrar que, ao longo de seus textos, o termo código é sobejamente utilizado. Reconhece, todavia, a pouca operacionalidade desse conceito, e advoga a favor do de enciclopédia. Para ele, o emprego do termo deve-se ao fato de ele já estar consagrado nos meios linguísticos e semióticos, não à sua excelência. $\mathrm{O}$ autor admite ainda que tem corrigido progressivamente o conceito de código em favor do de enciclopédia, talvez porque o primeiro só se possa resolver neste último. Além disso, segundo Eco, o que se vê em outros autores é o emprego do termo numa acepção mais ampla, próxima da de enciclopédia, conforme deixa claro o excerto:

Quem quer que no quadro da semiótica contemporânea tenha empregado a categoria de código não pretendia reduzi-la à de léxico simplificado, à de mera lista de homonímia. Tentava-se, certo ou errado, incluir também nesta categoria outras séries de regras e normas: em outras palavras, a categoria de código devia dar conta de uma gramática em seu conjunto (semântica e sintaxe, e até mesmo uma série de normas pragmáticas que dessem conta de uma competência executiva). (ECO, 1991c, p. 248) 
Segundo Eco, não se pode entender o código como uma cifra, mas sim como uma matriz que permite infinitas ocorrências, a nascente de um jogo. Eco pondera:

Mas nenhum jogo, nem mesmo o mais livre e inventivo, procede
ao acaso. Excluir o acaso não significa impor a todo custo o
modelo (empobrecido, formalizado e falaz) da necessidade.
Fica a fase intermediária da conjectura exposta sempre, como
Peirce sabia, ao princípio do falibilismo, regida pela confiança
de que as leis, que inventamos para explicar o informe, o
expliquem, de alguma maneira, nunca definitiva. (ECO, 1991C,
p. 290)

Ao que acrescenta:

Mas pode-se também pensar na matriz aberta de um jogo e na tendência a um clinamen que não seja necessariamente dada, mas de alguma maneira estabelecida continuamente pela atividade humana da semiose. Pode-se pensar na enciclopédia como labirinto, globalmente indescritível, sem admitir nem que não se possa descrever localmente, nem que, já que em todo caso existirá o labirinto, não possamos estudá-lo e construir seus percursos. (ECO, 1991C, p. 290)

Do cotejo entre Lopes e Eco, podemos assinalar como ponto de convergência, além da base teórica peirciana comum (um e outro opera com o conceito de interpretante), a noção de código. Como vimos, Lopes (1978) compreende três fases na interpretação de um texto: a semiose extradiscursiva, a intradiscursiva e a heterodiscursiva, sendo que cada uma delas faz remissão a um código específico. Eco não opera tal distinção. Parece-nos que isto se dá porque ele entende o processo de interpretação de um texto como a confluência desses três tipos de código, sem que haja necessariamente a precedência de um ou de outro, num mecanismo fundador de instruções indicadoras de um percurso de leitura.

No máximo, Eco admite, como vimos, um sentido literal, calcado no que está codificado, institucionalizado. Mas isto não quer dizer que o ato interpretativo obedeça rigorosamente a essa ordem. Segundo Eco, o que, com efeito, ocorre no ato interpretativo é uma série de tentativas, erros e acertos (a abdução de Peirce) na qual o intérprete joga com instruções provenientes da língua, do contexto e da ideologia (enquanto cultura), simultaneamente.

Em conformidade com essa forma de ver, podemos admitir que, assim como Eco, Lopes fala em código para lidar verdadeiramente com a noção de enciclopédia. O processo interpretativo postulado por 
v. 10 (esp.)

75-102 ago. 2020
Lopes nos conduz à mesma abertura aludida por Eco. Ressalte-se que o termo código tem acepções diferentes em Lopes (1978). Refere-se tanto à língua como à ideologia, esta menos formalizável que aquela. Além disto, Lopes (1978) admite uma estreita relação entre língua e ideologia, mas não explicita como isto se dá.

Para nós, a classificação de Lopes (1978) é válida por criar categorias operacionais, através das quais se pode descrever em fases sucessivas a desautomatização/atualização de uma função sígnica. Porém, na realidade, esse mecanismo é mais complexo do que pode sugerir essa proposta de interpretação trifásica.

Em suma, não obstante divirjam em alguns pontos, a proposta de Lopes e a de Eco guardam certa semelhança entre si. Conforme vimos, apesar de não empregar o termo enciclopédia, Lopes faz implicitamente uso dele, o que o aproxima de Eco. Cremos que o texto constitui o ponto para onde convergem o código da língua e o código ideológico (cultura), apontando, mediante instruções contexto-situacionais, para percursos de leitura.

\section{Referências}

BÜHLER, K. Teoría del lenguaje. Traducción de Julián Marías. Madrid: Revista de Occidente, 1950.

COQUET, J. Poética e linguística. In: GREIMAS, A. J. Ensaios de semiótica poética. Tradução de Heloysa de Lima Dantas. São Paulo: Cultrix/EDUSP, 1975

COSERIU, E. Teoria da linguagem e linguística geral. Tradução de Agostinho Dias Carneiro. Rio de Janeiro: Presença/EDUSP, 1979.

ECO, U. As formas do conteúdo. Tradução de Pérola de Carvalho. São Paulo: Perspectiva, 1974.

ECO, U. Conceito de texto. São Paulo: T. A. Queiroz/EDUSP, 1984.

ECO, U. A estrutura ausente. Tradução de Pérola de Carvalho. São Paulo: Perspectiva, 1991a.

ECO, U. Tratado geral de semiótica. Tradução de Antônio de Pádua Danesi e Gilson Cesar Cardoso de Souza. São Paulo: Perspectiva, 1991b.

ECO, U. Semiótica e filosofia da linguagem. Tradução de Mariarosaria Fabris e José Luiz Fiorin. São Paulo: Ática, 1991c.

ECO, U. Os limites da interpretação. Tradução de Pérola de Carvalho. São Paulo: Perspectiva, 1995.

FREGE, G. Sobre o Sentido e a Referência. In: ALCOFORADO, Paulo (org. e 
trad.). Lógica e Filosofia da Linguagem. São Paulo, Cultrix/Edusp, 1978.

GREIMAS, A. J. Ensaios de semiótica poética. Tradução de Anne Arnichand e Álvaro Lorencini. São Paulo: Cultrix/EDUSP, 1976.

HALLIDAY, M. A. K. Estrutura e função da linguagem. In: LYONS, John (org.). Novos horizontes em linguística. Tradução de Jesus Antônio Durigan. São Paulo: Cultrix/EDUSP, 1976.

HALLIDAY, M. A. K. El lenguaje como semiótica social: la interpretación social del lenguaje y del significado. Traducción de Jorge Ferreiro Santana. México: Fondo de Cultura Economica, 1978.

HALLIDAY, M. A. K. An introduction to functional grammar. London: Edward Arnold, 1985.

HJELMSLEV, L. Prolegômenos a uma teoria da linguagem. Tradução de J. Teixeira Coelho Netto. São Paulo: Perspectiva, 1975.

HYMES, D. On Communicative Competence. In PRIDE, J. B.; HOLMES, J. Sociolinguistics. England: Penguin Books, 1972. p. 269-293

JAKOBSON, R. Linguística e comunicação. Tradução de Izidoro Blikstein e José Paulo Paes. São Paulo: Cultrix, s/d.

KLOEPFER, R. Poética e linguística. Coimbra: Almedina, 1984.

LOBATO, L. M. P. A semântica na linguística moderna: o léxico. Rio de Janeiro: Francisco Alves, 1977.

LOPES, E. Fundamentos da linguística contemporânea. São Paulo: Cultrix, s/d.

LOPES, E. Discurso, texto e significação: uma teoria do interpretante. São Paulo: Cultrix/Secretaria da Cultura, Ciência e Tecnologia do Estado de São Paulo, 1978.

MORRIS, Ch. Fundamentos de la teoria de los signos. Barcelona: Paidós, 1985.

MUKAROVSKÝ, J. A denominação poética e a função estética da língua. In: TOLEDO, D. (org.). Círculo Linguístico de Praga: estruturalismo e semiologia. Traduções de Zênia de Faria, Reasylvia Toledo e Dionísio Toledo. Porto Alegre: Globo, 1978.

OGDEN, C. K. e RICHARDS, I. A. O significado de significado. Rio de Janeiro: Zahar, 1976.

PEIRCE, Ch. S. Semiótica. Tradução de José Teixeira Coelho Neto. São Paulo: Perspectiva, 1995.

RIFFATERRE, M. Estilística estrutural. Tradução de Anne Arnichand e Álvaro Lorencini. São Paulo: Cultrix, 1973.

RIFFATERRE, M. A produção do texto. Tradução de Eliane Fitipaldi Pereira Lima de Paiva. São Paulo: Martins Fontes, 1989. 
V. 10 (esp.)

75-102

ago.

2020

SANTAELLA, L. A teoria geral dos signos: semiose e autogeração. São Paulo: Ática, 1995.

SAUSSURE, F. de. Curso de linguística geral. Tradução de Antônio Chelini, José Paulo Paes e Izidoro Blikstein. São Paulo: Cultrix, s/d.

TOLEDO, D. (org.). Círculo linguístico de Praga: estruturalismo e semiologia. Porto Alegre: Globo, 1978.

VANOYE, F. Usos da Linguagem. Tradução e adaptação de Clarisse Madureira Sabóia, Ester Miriam Gebara, Haquira Osakabe e Michel Lahud. São Paulo: Martins Fontes, 1986. 